\title{
Práticas e percepções docentes e suas relações com o prestígio e clima escolar das escolas públicas do município do Rio de Janeiro*
}

\author{
Márcia de Sousa Terra Brito
}

Faculdade de Educação da Universidade Federal do Rio de Janeiro

\section{Marcio da Costa}

Faculdade de Educação da Universidade Federal do Rio de Janeiro, Programa de Pós-Graduação em Educação

\section{Introdução}

O esforço para compreender a dinâmica dos estabelecimentos de ensino como organizações tem sido recente nas pesquisas da educação brasileira, de certo modo impulsionadas pela constatação de deficiências em nosso ensino fundamental, especialmente nas escolas públicas. Frequentadas pela maioria da população brasileira, tais escolas em geral apresentam resultados escolares insatisfatórios e dificuldades de melhoria substantiva. E, apesar de as vagas para o ensino fundamental terem sido ampliadas nas últimas décadas, Klein (2007) mostra que a conclusão desse nível de ensino ainda não foi universalizada e que as taxas de repetência e evasão deixaram de cair nos últimos anos.

Essas constatações têm sido agregadas à discussão sobre a qualidade das escolas brasileiras, concluin-

* Pesquisa financiada pelo CNPq, por meio de Bolsa de Produtividade em Pesquisa e do Edital Universal. Contou com a participação de estudantes que integram o Grupo de Estudos dos Sistemas Educacionais da Faculdade de Educação da Universidade Federal do Rio de Janeiro. do que não basta garantir vagas nas escolas públicas para toda a população em idade escolar; é necessário também ter qualidade e equidade na oferta educativa. Nesse sentido, Franco et al. (2007) identificaram a persistência dos problemas de fluxo de alunos nas escolas brasileiras associados ao baixo desempenho, destacando a importância de fatores promotores de equidade intraescolar que promovam a moderação ou superação da desigualdade de desempenho escolar dos alunos.

Já de longa data, pesquisas internacionais (Mortimore, 1997) convergem para conclusões que apontam a escola e particularmente o professorado como um dos elementos mais influentes no processo de aprendizagem. Professores, por meio das práticas pedagógicas, podem influenciar significativamente a trajetória escolar dos alunos, contribuindo para o sucesso escolar, especialmente daqueles com maiores dificuldades educacionais. Apesar de recentes no Brasil, estudos nessa direção também têm apresentado resultados bastante significativos, ratificando a importância da instituição de ensino para o êxito ou fracasso do aluno, como mostram dados de Alves e Soares (2007). 
Partindo de tais pressupostos, o trabalho que se segue buscou identificar nas formas de organização interna da escola e nas interações dos professores com a instituição de ensino fatores que permitam melhor compreender a dinâmica educativa, em especial da rede pública do município do Rio de Janeiro.

Privilegiando a abordagem teórica de clima e prestígio escolar, objetivou-se investigar em que medida as características do ambiente escolar podem influenciar a prática docente, ${ }^{1}$ que potencialmente se reflete no desempenho e na trajetória escolar de seus alunos. Procura-se, assim, conectar "clima escolar" e rendimento de alunos por uma faceta pouco explorada dessa provável relação: a mediação do professorado.

Estudos com referência ao clima escolar buscam analisar padrões de interações sociais presentes no contexto escolar que podem facilitar ou dificultar o trabalho coletivo e o diálogo entre os diferentes atores do processo pedagógico, aspectos fundamentais na dinâmica educativa.

Apesar de atualmente se encontrar uma multiplicidade de definições sobre clima escolar, a bibliografia sobre esse tema tem em comum a ideia de clima como percepção dos indivíduos sobre o ambiente circundante e tem demonstrado que a forma como os indivíduos percebem coletivamente essa "atmosfera" traz significativas influências sobre o comportamento dos grupos. Para Cunha e Costa (2009), a definição do clima escolar que explicita melhor o conceito corresponde ao conjunto das expectativas recíprocas compartilhadas pelos indivíduos em um ambiente institucional.

Dessa forma, o pensamento predominante nessas pesquisas traz a perspectiva de que uma escola na qual as relações entre os diferentes membros da comunidade educacional são positivas favorece um bom clima

${ }^{1}$ A prática docente é aqui entendida como uma ação de produção do conhecimento decorrente da reflexão dos professores sobre o que, como e para quem ensinar, da postura docente nas relações com alunos/as, e de suas inter-relações no sistema social, político, econômico e cultural (Ghedin, 2002). de trabalho, e serão obtidos resultados favoráveis no processo pedagógico, não se limitando exclusivamente ao rendimento acadêmico.

Fox (apud Cunha e Costa, 2009) especifica:

\begin{abstract}
o clima de uma escola resulta do tipo de programa, dos processos utilizados, das condições ambientes que caracterizam a escola como uma instituição e como um agrupamento de alunos, dos departamentos, do pessoal e dos membros da direção. Cada escola possui o seu clima próprio. O clima determina a qualidade de vida e a produtividade dos docentes e dos alunos. O clima é um fator crítico para a saúde e para a eficácia de uma escola. (p. 12-13)
\end{abstract}

Não foram encontrados nas pesquisas nacionais estudos que abordem a relação direta entre clima escolar e o professor. As discussões e os debates com foco no professor comumente giram em torno de sua formação. A qualidade dessa formação é entendida como a grande norteadora dos resultados pedagógicos desses profissionais junto aos alunos. O trecho a seguir ilustra essa constatação:

\footnotetext{
São Paulo - Dois dos maiores nomes da educação brasileira dos últimos 15 anos, o atual ministro Fernando Haddad e o ex-ocupante da pasta e hoje secretário estadual Paulo Renato Souza, acreditam que os cursos de formação de professores precisam mudar para que o ensino no país melhore. (Portal do Estadão em 8/6/2009)
}

Não desconsiderando a grande relevância do tema formação de professores, o estudo do clima escolar com foco no professor, embora comumente pouco considerado nas pesquisas brasileiras, permite uma variação de perspectivas investigativas para além da formação docente, possibilitando um olhar igualmente promissor sobre as características próprias da escola e como esse professor vai interagir e agir nesse espaço. A importância do clima de trabalho sobre o indivíduo tem sido evidenciada na literatura como um dos fatores para a compreensão de sua conduta: "para podermos determinar as causas do comportamento de um indivíduo em situação de trabalho, precisamos tomar em 
linha de conta as suas características pessoais, mas também o seu ambiente ou clima de trabalho (Brunet, 1995, p. 125).

Além da análise do clima escolar, a pesquisa aqui apresentada considerou ainda diferenças entre escolas quanto ao prestígio escolar, tomando como referência as significativas diferenças de desempenho entre as escolas públicas municipais do Rio de Janeiro, denunciadas nas avaliações de larga escala (Brasil/ MEC, 2007).

Embora o prestígio escolar não deva ser considerado equivalente ao desempenho escolar, tendo em vista que a reputação da escola é construída em um tempo longo, estando sujeita a outros elementos constitutivos, há uma forte ligação entre desempenho e prestígio. Cerdeira (2008) aponta a necessidade que as instituições de prestígio da rede privada têm em manter o status de prestígio, e para tanto se empenham em atrair e manter alunos com melhores condições sociais, culturais e acadêmicas.

Reconhecendo as limitações e deficiências na oferta do ensino público no país, tal fenômeno tem sido analisado também nas escolas públicas. Costa e Koslinski (2009) identificaram a existência de fortes hierarquias entre as escolas públicas do município do Rio de Janeiro, tanto entre as escolas estudadas quanto dentro das próprias escolas (entre turmas e turnos), sugerindo relação estreita entre o prestígio escolar e as características de funcionamento da escola. Os autores indicam ainda que o sistema oficial de ingresso na escola pública não consegue garantir uma distribuição neutra das crianças entre as escolas, e aponta a ocorrência de mecanismos informais de seleção que influem na composição do alunado, contribuindo significativamente para a diferenciação dos estabelecimentos de ensino público.

O prestígio escolar nesse contexto torna-se um fator relevante na medida em que contribui para atuar como elemento diferenciador da clientela. Uma escola, ao ser mais disputada que outras, passa a dispor de condições para seleção de alunos com características vantajosas, reproduzindo e alimentando o status escolar que a distingue das demais, caracterizando o fenô- meno denominado "circularidade virtuosa", conforme referido por Brandão (2000). Assim, estabelecimentos de menor prestígio tenderiam a abarcar os mais desfavorecidos, e os estabelecimentos mais prestigiados conseguiriam selecionar os mais afortunados. Tal fato evidencia que a escola pode não apenas se limitar a reproduzir as desigualdades como também acentuálas. Logo, a importância da influência da instituição educativa sobre a vida escolar do aluno não pode ser ignorada.

Aspectos qualitativos como clima e prestígio escolar contribuem, portanto, para pôr em evidência características do ambiente escolar, como valores, hábitos, atitudes, relações de poder, que podem ganhar importância a ponto de direcionar o comportamento dos indivíduos dentro da instituição de ensino, e o professor, nesse contexto, adquire posição privilegiada como sujeito ativo de percepção das instituições educativas.

Os professores que integram o sistema público de ensino do município do Rio de Janeiro possuem grande mobilidade de alocação entre escolas, em virtude da grande oferta de estabelecimentos escolares, podendo escolher, em certas condições, em qual escola deseja lecionar e trocar de escola se assim for de seu interesse, o que lhes permite vivenciar experiências escolares distintas, na medida em que podem trabalhar em escolas com características díspares bem como identificar se a prática educativa que exercem nas diferentes escolas pode vir a ser influenciada pelas relações que estabelecem com as instituições.

Nóvoa (1995) destaca que a utilização de modelos de análise que introduzem alguns conceitos políticos (recorrendo a relações de poder, interesses, controle etc.) e simbólicos (significados que os atores dão aos acontecimentos, caráter contingente dos processos educacionais, entre outros) permite uma compreensão mais apurada da construção das estruturas da organização escolar.

Brunet (1995) afirma ainda que as organizações escolares, ainda que estejam integradas num contexto cultural mais amplo, produzem uma cultura interna que lhes é própria e que exprime os valores e as crenças 
que os membros da organização partilham. Assim, a escola não se limita apenas a reproduzir as normas e os valores de um macrossistema, como também não pode ser vista exclusivamente como um microuniverso. Em tal perspectiva, Nóvoa (1995) faz referência à emergência de uma sociologia das organizações escolares que se propõe a optar por um nível mezzo de compreensão e de intervenção.

Dessa forma, entende-se que conhecer e compreender as dinâmicas das instituições escolares por meio das percepções docentes sobre o prestígio e clima escolar é um campo teórico rico de análise, em especial na escola pública, no sentido de perceber como tais escolas em suas formas internas podem, por meio da diferenciação existente entre elas, promover oportunidades educacionais ou contribuir para a estruturação das desigualdades sociais.

\section{Seleção das escolas, professores e metodologia utilizada}

Tendo como referência a avaliação da Prova Brasil (2007) e com foco nas escolas públicas que integram a rede municipal do Rio de Janeiro, foram selecionadas, nesse contexto, as cem escolas que obtiveram os melhores resultados na avaliação e as cem escolas com resultados inferiores, dentre o universo de 367 escolas públicas municipais do Rio de Janeiro que avaliaram as turmas do $9^{\circ}$ ano (antiga $8^{\mathrm{a}}$ série) em 2007. As escolas selecionadas de melhor classificação e entendidas neste estudo como de maior prestígio foram aqui denominadas E1; as escolas de menor classificação, entendidas como de menor prestígio, foram identificadas como E2.

A rede pública da cidade do Rio de Janeiro possui hoje um dos maiores sistemas municipais de ensino do país; a grande diversidade dessa rede de ensino permite traçar distinções significativas entre as cem escolas com melhor desempenho e, provavelmente, com boas reputações e as cem com pior desempenho e suposta reputação inferior.

A seleção dos professores nas escolas deu-se com base em informações junto à SME-RJ, a fim de verificar se existiam professores que trabalhavam simultaneamente nos dois extremos da distribuição das escolas selecionadas segundo o critério de proficiência média na $8^{\mathrm{a}}$ série (agora $9^{\circ}$ ano). Buscou-se saber se existiam professores que trabalhavam ao mesmo tempo numa das cem escolas de melhor classificação e em uma das cem escolas de mais baixa classificação. Foi-nos fornecida uma lista nominal de sessenta professores que se enquadravam nesse critério, e a partir dessa lista foi possível entrevistar um total de vinte professores. Dada a escassez de professores que atendessem ao critério amostral escolhido, optou-se por um trabalho de natureza qualitativa.

A análise dos dados configurou-se na elaboração de uma árvore de categorias e subcategorias a partir do roteiro de entrevista e das informações coletadas (características do clima e prestígio das escolas; percepção de diferenças entre escolas; caracterização do perfil dos alunos nas escolas; atitudes dos professores nas diferentes escolas), as quais foram incorporadas ao software NVIVO, que possibilitou a organização dos dados dispersos em vários contextos.

\section{Perfil dos professores entrevistados}

A predominância do gênero feminino foi um fator de destaque: dentre os vinte professores entrevistados, 17 eram mulheres, o que sugere e reforça o que tem sido indicado nas pesquisas sobre gênero na profissão docente sobre a feminização da profissão nas escolas brasileiras. O tempo de docência, que dentre outros fatores contribui para indicar maior ou menor experiência dos docentes nas escolas públicas, indicou que os professores possuíam, em média, dezoito anos de trabalho na rede pública municipal, e, dentre os vinte professores entrevistados, seis nunca lecionaram em escolas privadas.

\section{Alguns resultados}

Uma das primeiras questões apresentadas aos professores entrevistados buscava identificar se eles percebiam diferenças entre as duas escolas nas quais 
lecionavam. O tipo de diferença não foi especificado aos entrevistados. A única informação dada no início de cada entrevista correspondia ao nome das duas escolas nas quais os professores lecionavam e a informação de que tais escolas haviam obtido resultados distintos na avaliação da Prova Brasil de 2007, não sendo divulgado, portanto, qual escola obteve melhor ou pior resultado.

Todos os professores entrevistados afirmaram existir diferenças significativas entre as duas escolas nas quais lecionavam. Embora todos tenham relatado desconhecer ou não se lembrar da nota de suas escolas na avaliação da Prova Brasil no referido ano, todos os professores sugeriram enfática e corretamente a escola que poderia ter alcançado o melhor resultado. $\mathrm{O}$ fato de a opinião dos professores sobre o desempenho das escolas ter convergido com os resultados da Prova Brasil de 2007 reforça em alguma medida a significância dos dados dessa avaliação, bem como revela a coerência da percepção dos professores sobre a existência de diferenças entre as escolas em que lecionam.

Os trechos a seguir exemplificam a percepção dos professores sobre diferenças entre as escolas:

As diferenças são gritantes. Quando eu cheguei aqui na E1, tem um ano, e aí eu fiquei chocada, que era uma diferença estúpida. Apesar de que a E2 em que eu estou não é das piores, é uma escola razoável, não é dentro do morro, dentro da favela, não, mas ainda assim é bem diferente daqui [E1]. (Professor 1)

Percebo diferenças, sim. A gente enquanto professor tenta superar essas diferenças. Acho que a forma da escola trabalhar as dificuldades é diferente. Eu não diria que os professores aqui são melhores que os de lá, não, mas acho que os alunos e a forma de se trabalhar aqui [E1] contribuem para esse perfil da escola. (Professor 4)

Percebe-se, nesse primeiro momento, que os professores tendem a indicar como fator predominante das diferenças entre as escolas o perfil dos alunos que a escola atende, sendo esse perfil caracterizado pelo nível socioeconômico da comunidade ou bairro do qual os alunos são oriundos.
Muitos dos professores entrevistados lecionavam em escolas localizadas no mesmo bairro ou em bairros próximos e relataram que algumas escolas, embora situadas em uma mesma região, agrupam alunos com perfis semelhantes (oriundos da mesma comunidade ou com dificuldades parecidas), ou seja, uma escola do mesmo bairro consegue agrupar alunos com características semelhantes entre si, contrastando com outra escola também situada no mesmo bairro que agrupa alunos com outras características. Tal fato contribui para reforçar as diferenças entre as escolas, como se verifica nas falas a seguir:

O alunado realmente é totalmente diferente, porque aqui [E2] a gente recebe um pessoal mais despreparado em todos os aspectos e na outra [E1] é mais selecionado. (Professor 8)

Não é basicamente a mesma clientela. O que varia um pouco é a localidade aqui dentro do $\mathrm{A}^{*}$ [nome do bairro], duma parte de um bairro estar mais direcionada aqui pra E2 e outra parte do bairro estar mais direcionada pra E1. Na E1 eu acho que eles têm um contexto social, econômico um pouco melhor, aqui [E2] acho que eles são um pouco mais carentes. (Professor 13)

A homogeneização do perfil de alunos nas escolas, como mencionado pelos professores, indica que tais escolas ou os próprios alunos/responsáveis podem estar fazendo uso de estratégias diferenciadas de oferta ou obtenção de vagas nas escolas públicas. E, como sugerem estudos de Costa e Koslinski (2009), a ausência de regulação ou critérios claros e explícitos sobre a oferta de vagas aos alunos no ensino fundamental da rede pública de ensino pode contribuir para desigualdades da oferta educativa entre as escolas.

Foi possível identificar, dentre as vinte entrevistas, alguns relatos que reforçam essa tese; neles foram mencionados pelos professores alguns mecanismos de diferenciação da oferta educativa pela gestão da escola. Os referidos relatos correspondiam às escolas de maior prestígio, como vemos a seguir: 
Existe diferença na gestão, uma firmeza maior nas atitudes; essa firmeza até na hora de escolher quem vai entrar naquela escola. Quem é o aluno, que aluno que está entrando ali. E lá na E1 tem isso. Como é eu não sei exatamente, mas os alunos ali são mais selecionados. (Professor 8)

Hoje não dá para a escola selecionar aluno, nós não temos um mecanismo de seleção, você não pode simplesmente excluir. Então, eu vejo, sim, uma pressão maior da direção da E1. Dentro de uma conversa, ela fala assim pro responsável: “olha, ele [aluno] não tem mais interesse, ele está fora da idade, ele está precisando de outras perspectivas, de outras coisas". Aí orienta: "olha, tem um curso assim, assim" "tem uma escola noturna tal", e encaminha. (Professor 10)

A percepção de diferenças entre as escolas, portanto, foi claramente constatada por todos os professores entrevistados, e os relatos indicaram a relação dessas diferenças com fatores extraescolares evidenciados pelas características socioeconômicas dos alunos e ainda por fatores intraescolares correspondentes às ações diferenciadas em cada escola, o que contribui para manter e acentuar as diferenças nessas instituições.

Outra questão trazida aos professores buscava identificar aspectos que reforçassem a caracterização do prestígio escolar para além da classificação na avaliação da Prova Brasil (2007). A demanda de alunos constituiu um fator relevante: as escolas de maior prestígio corresponderam às escolas mais procuradas pela comunidade. "A E1 é bem mais procurada, porque os pais que procuram lá são mais interessados, querem o melhor para os filhos, e o pessoal sabe que essa escola aqui [E1] tem uma fama boa, é difícil de conseguir vaga" (Professor 9).

A caracterização do clima escolar buscou identificar as percepções docentes sobre suas respectivas escolas, na tentativa de apreender as características das instituições percebidas no dia a dia escolar pelos professores. O relatório do SAEB 2003 (Brasil/MEC/INEP, 2004) aponta que é de fundamental importância que os alunos sejam conduzidos a um bom relacionamento coletivo, produtivo e prazeroso nas escolas, indicando ser responsabilidade direta dos professores e diretores a criação desse bom "clima" de relações; a construção desse ambiente favorável está relacionado às características concretas da estrutura e do funcionamento das escolas.

\begin{abstract}
A gestão aqui [E1] é mais atuante e isso favorece esse perfil da escola, ela é empenhada, corre atrás de manter as coisas em ordem. (Professor 4)

Na E2 a direção estressa muito os professores, ela é esforçada, mas o jeito dela de impor ordem causa desgaste na equipe da escola. Na maioria das vezes os alunos dão muito trabalho mesmo pra gente. Isso a gente já espera, mas quando a equipe da escola não coopera, não deixa os professores à vontade, não tem um diálogo legal, está sempre reclamando ou com a cara amarrada, aí fica mais difícil de aguentar. (Professor 6)
\end{abstract}

$\mathrm{O}$ relacionamento que o professor estabelece com a unidade escolar é evidenciado também por diferenças nas relações estabelecidas com os alunos nas respectivas escolas. Os relatos indicam que o convívio com os alunos na E2 tende a ser mais turbulento e desgastante.

\footnotetext{
Vejo um relacionamento mais conflituoso com os alunos da E2. As escolas que têm alunos com maiores dificuldades, que atendem uma clientela de comunidade mais carente, como a E2, são as mais desfavorecidas, com falta de professores e outros funcionários, falta também uma cobrança mais específica da família. (Professor 4)

O relacionamento dos professores é diferente nessas escolas porque são demandas diferentes, são comunidades diferentes. Na E1 os alunos são mais interessados, têm mais prazer em ir para a escola. Quando eles terminam o ensino fundamental eles voltam, vários voltam para visitar a gente, e se deixar eles estão sempre lá. Existe um relacionamento mais afetuoso com os alunos ali naquela escola [E1]. (Professor 14)
}

A diferença nas relações entre professores e os responsáveis dos alunos também foi identificada e sugere reflexo da relação professor-aluno. De acordo com o relato dos professores, existem maiores dificuldades em atrair a participação dos pais nas escolas de menor prestígio [E2]; o diálogo e a interação entre responsáveis e a escola são mais conturbados nessas escolas. 
Se uma criança está com muita dificuldade e os pais não se importam, a gente se mata para conseguir um resultado legal, chamamos o pai na escola, e quando eles não demonstram interesse em cobrar dos filhos, e isso acontece muito na E2, aí você vai perdendo as forças, vai ficando desmotivado. (Professor 4)

Nas escolas em que a coisa é mais certinha, como lá na E1, onde as coisas funcionam melhor, os pais são mais presentes.

(Professor 8)

Não foram identificadas diferenças significativas no relacionamento entre os professores nas diferentes escolas. No entanto, os depoimentos destacaram um aspecto desfavorável ao progresso escolar dos alunos nas escolas de menor prestígio [E2], em função de maior rotatividade dos professores, mostrando maior instabilidade do trabalho docente nessas escolas.

Foi possível identificar, nas escolas em estudo, maior adesão e clareza quanto às normas e aos valores estabelecidos nas escolas de maior prestígio [E1]; as escolas menos prestigiadas [E2] são indicadas como escolas de convívio social mais difícil, por não terem critérios bem definidos junto aos alunos e professores. A forma de gestão é destacada pelos professores como fator chave no direcionamento e constituição da cultura interna na escola.

\footnotetext{
$\mathrm{Na}$ E1 os alunos são submetidos a um maior grau de controle e exigências, por exemplo, com relação até ao uniforme; se o aluno aparece sem uniforme é cobrado dos pais, mandase bilhete. É cobrado mais da gente também, dos próprios professores, e isso reflete na conduta dos alunos e dos próprios professores. Na outra escola [E2] isso já não é tão forte. (Professor 15)

Quando a gente recebe alunos de outra escola, como da E2, eles chegam aqui [E1] meio alucinados, sem modos, mas rapidinho eles percebem como as coisas funcionam e mudam, então acho que isso pode ser aprendido. (Professor 4)
}

Com base nos relatos dos professores foi possível identificar claramente a existência de distinções no clima escolar das escolas em que lecionavam. As percepções docentes destacaram uma atmosfera de encorajamento e altas exigências, cordialidade, relações mais próximas com a família e os alunos nas escolas de maior prestígio [E1]. Foi possível constatar ainda que os professores tendem a reconhecer que os aspectos que constituem o clima escolar exercem influências significativas na conduta dos alunos e dos professores nas respectivas escolas. Os professores indicam ter maior satisfação em trabalhar nas escolas onde há regras claras, maior comunicação entre a equipe e maior disciplina.

\footnotetext{
Claro que na E1 tem problemas também, isso você vai encontrar em qualquer lugar, mas a E1 é melhor. Em termos de ambiente escolar, aqui [E1] é melhor de trabalhar, a dinâmica dos professores com a direção e os alunos é melhor. (Professor 3)

Na E1 você tem maior liberdade e apoio para desenvolver seu trabalho. Esse tipo de coisa é diferente nessa escola e isso vai fazer uma grande diferença no resultado do seu trabalho. (Professor 17)
}

A literatura sobre clima escolar tem destacado a figura do gestor como um agente crucial na promoção de um clima favorável nas escolas, e os relatos dos professores colaboram para evidenciar a influência da gestão na construção desse bom clima de trabalho. Aspectos como gestão democrática, mobilização comunitária e fortalecimento da equipe parecem contribuir para promover o maior envolvimento dos professores nas atividades escolares, favorecendo o aprendizado escolar dos alunos.

Uma das questões trazidas aos professores entrevistados correspondia às expectativas deles com relação aos alunos nas diferentes escolas. Essas expectativas contribuem para direcionar a atitude dos professores diante dos alunos. Estudos nesse sentido já são clássicos e evidenciam que as expectativas da equipe escolar correspondem ao estabelecimento de metas, objetivos e desempenho a serem alcançados por seus alunos e sugerem que baixas expectativas podem funcionar com "profecias autorrealizadoras" na sala de aula, por atuarem como determinantes não intencionais da capacidade intelectual dos alunos (Rosenthal \& Jacobson, 1971). 
Nas entrevistas realizadas, com exceção de duas professoras, todos relataram expectativas diferentes em relação ao desempenho dos alunos, sendo as mais elevadas correspondentes aos alunos das escolas de maior prestígio [E1], como indica o depoimento a seguir:

Sim, com certeza! Eu sei que lá [E2] a gente fala de faculdade, fala de futuro com eles, mas a maioria não consegue nem vai consegui terminar o ensino médio. E aqui [E1] a gente recebe visita de alunos que estão na faculdade, felizes da vida, quase se formando. Então as expectativas são bem diferentes. (Professor 15)

Ao serem questionados sobre mudanças de atitudes em função das diferentes escolas, todos os vinte professores foram claros em afirmar que, em decorrência das características das escolas, de fato era necessário modificar suas ações. Os relatos a seguir caracterizam a fala dos professores:

\footnotetext{
Modifico, claro que modifico, eu modifico de acordo com o ambiente, a disciplina, o interesse do aluno; você aprende a dançar conforme a música. Se não a sensação de frustração se torna maior. Se não fizer isso, é como se você estivesse remando contra a maré, então tem que se adaptar. (Professor 2)

Sim, de alguma maneira sim, quer dizer, não que eu queira mudar, eu tento agir da mesma forma nas duas escolas, mas eu percebo que aqui [E2] eu fico mais desmotivada, mais aborrecida, porque o aluno não corresponde às coisas que você propõe fazer, as dificuldades de trabalho são maiores. Então você acaba trabalhando diferente. (Professor 17)
}

É importante ressaltar que vários professores demonstraram ter aguda consciência da diferença de atitudes e expectativas que desenvolvem em cada escola, o quanto isso pode estar associado a esquemas reprodutores de injustiças, mas também das limitações que enfrentam para confrontar a questão no plano individual. Parecem perceber a necessidade de esquemas de ação coletiva não acessíveis no plano individual das rotinas fragmentadas.

As diferenças de abordagem dos conteúdos nas diferentes escolas também foram mencionadas pelos professores. Nas escolas de baixo prestígio [E2], foi indicada uma tendência à simplificação dos conteúdos, e, em alguns casos, foi apontada a falta de oportunidade de esses conteúdos serem trabalhados em decorrência das dificuldades apresentadas pelos alunos nessas escolas.

Verificou-se ainda que, em virtude das diferenças de abordagem do conteúdo nessas escolas, as avaliações ministradas junto aos alunos também são diferenciadas. Nas escolas de maior prestígio, é indicada exigência maior dos assuntos trabalhados em aula: "As provas eu não posso cobrar igual, às vezes faço prova com consulta na E2, ou uma prova com dificuldade menor que a da E1, tenho que trabalhar no ritmo deles" (Professor 16).

A opinião dos professores sobre como veem as diferenças entre as escolas revelou certa naturalização dessas diferenças. De modo geral, os professores mencionaram que essas diferenças refletem as diferenças existentes na sociedade brasileira. E que a escola apenas revela um problema social maior.

Ao serem indagados sobre a que atribuem essas diferenças entre as escolas, os professores foram unânimes em indicar o aluno, a família e aspectos socioeconômicos como fatores principais. A gestão escolar foi o segundo aspecto mais mencionado pelos professores. Apenas um relato mencionou a ação dos professores nas escolas como fator de influência das diferenças. A tendência predominante no discurso dos professores entrevistados corresponde à força determinante dos aspectos extraescolares sobre as diferenças escolares.

\footnotetext{
A participação da família nos estudos dos filhos e a conscientização da comunidade sobre a importância da escola. A direção também é importante, mas ela sozinha não vai fazer tudo, não vai dar conta de tudo, precisa todos chegarem juntos e aí a família tem um peso muito grande. (Professor 17)
}

É interessante verificar ainda que houve certa dificuldade em responder à pergunta sobre como alterar as diferenças entre as escolas, especialmente nas mais 
"fracas", pois, para a maioria dos professores, essa questão sugeriu tamanha complexidade que eles se viram incapazes de responder. A fala a seguir ilustra essa percepção: "Essa é a pergunta de seis milhões de dólares! Não tem uma fórmula! Mas eu acho que deveria ter, acima de tudo, trabalhos sociais pertinentes" (Professor 18).

Para outros professores, essa questão foi respondida destacando a impotência da escola diante dessas diferenças:

\footnotetext{
Não tem como melhorar. A gente não tem estrutura capaz, porque só você, sozinho, você não consegue. Teria que ter uma intervenção da CRE, selecionar profissionais preparados para encarar uma realidade difícil, porque ali [E2] não é exceção, não, deve ter outras escolas com essas realidades em comunidades difíceis também. Então nesse caso eu acho que teria que ter uma coisa especial, um tratamento especial para essas escolas. (Professor 3)
}

Dentre os professores que foram mais específicos, a ênfase dada para alterar as diferenças entre as escolas recai sobre aspectos relacionados à participação da família na educação dos filhos, às políticas públicas eficientes e maior assistência do governo às escolas que apresentam maiores dificuldades:

Eu acho que só mesmo o governo investir na família, porque não é só a educação que vai resolver o problema, é a família... Dar infraestrutura para a família, para que os pais possam ter aquela responsabilidade, de fato, de cuidar dos filhos, de estarem presentes. (Professor 11)

Um maior comprometimento da família, a valorização do profissional de educação é fundamental em todos os sentidos, salarial, apoio em relação a projetos das escolas. Porque a coisa está meio devagar mesmo, estamos andando com as próprias pernas há muito tempo. Apoio, isso ajuda bastante. (Professor 19)

É fundamental, para a escola funcionar bem, ter recursos humanos. Transferiram para a gente tanta responsabilidade, mas não deram nem qualificação técnica, nem material humano para fazer isso tudo, então esse é outro aspecto importantíssimo, a meu ver. (Professor 6)

\section{Considerações finais}

Cabe ressaltar que, mediante a complexidade de fatores que envolvem uma dada realidade escolar, aliada às limitações metodológicas desta pesquisa, não foi intenção deste estudo estabelecer generalizações sobre o sistema escolar aqui analisado; os dados obtidos são descritivos e sugestivos. Contudo, a partir das informações mapeadas foi possível levantar algumas proposições relevantes, que podem ajudar a compreender melhor as interações educativas estabelecidas nas escolas em análise bem como aspectos da estrutura de oferta educacional desigual.

As entrevistas indicaram que, além de perceberem diferenças relevantes entre as escolas do município do Rio de Janeiro, os professores tendem a adaptar sua ação pedagógica junto aos alunos em conformidade com as dificuldades ou vantagens que a escola apresenta, podendo, contudo, estar de alguma forma contribuindo para a reprodução das desigualdades educativas.

Os professores, embora identifiquem diferenças nos aspectos intraescolares, como o clima escolar (diferenças de relacionamento com a direção, pais e alunos, mudança de atitude dos professores diante dos alunos, diferenças na abordagem dos conteúdos e nas formas de avaliação, uso diferenciado dos recursos escolares) e o prestígio escolar (indicação de seleção de alunos nas escolas e diferenciação nos critérios de oferta escolar), tendem a não vincular as diferenças existentes nas escolas com as relações intraescolares estabelecidas em cada instituição.

Para os entrevistados, o fator que move essas diferenças entre as escolas é o perfil dos alunos de cada unidade escolar, frequentemente associado às características de interação da família com a escola e a fatores socioeconômicos. Apesar de evidenciarem a grande importância da gestão escolar para a organização e estruturação da escola, o peso de fatores extraescolares no discurso dos professores é, para eles, o ponto determinante para a constituição das diferenças escolares.

Assim, foi possível perceber uma tendência dos 
professores de eximir a escola de qualquer eventual responsabilidade na promoção dessas diferenças, o que fez que também fosse excluído do discurso dos professores qualquer tipo de relação entre as ações docentes e as características diferenciadas das escolas. O problema dessa perspectiva é que, ao imputar os problemas enfrentados pela escola a fatores exclusivamente externos, o professor se isenta de qualquer possibilidade concreta de atuação no sentido de favorecer as escolas com maiores dificuldades.

Não se pretende aqui, todavia, martirizar ou responsabilizar concentradamente o professorado pelo quadro desigual observado. Afinal, como a sociologia da educação tão fartamente já demonstrou, os fatores extraescolares são de fato bem mais fortes na explicação das diferenças de desempenho e trajetória escolar de alunos, em todos os sistemas educacionais pesquisados. Nossos professores parecem de alguma forma compartilhar dessa percepção, ainda que de forma não teorizada. A preocupação maior é quanto à tendência observada de naturalização das diferenças e quanto ao correspondente senso de impotência diante do quadro. Há, porém, a ressalva de que, também como a literatura sobre efeito-escola e efetividade escolar aponta, ainda que presentes no plano individual, os elementos para ruptura do quadro observado demandam lógicas de ação coletiva eficazes e, sobretudo, políticas públicas atentas ao problema. Não parece ser casual que os ambientes escolares típicos dos "círculos virtuosos" sejam raros no contexto estudado - escolas públicas "comuns" -, dependendo mais da existência ocasional, não planejada, de algum tipo de liderança carismática ou de fortes mecanismos de segregação social.

Verifica-se assim a necessidade de estudos mais aprofundados sobre o cotidiano das escolas e do trabalho docente com o objetivo de contribuir para a compreensão de como nossas escolas podem ajudar a favorecer a permanência e a aprendizagem dos alunos, independente do peso indiscutível das características sociais, econômicas e culturais que carregam, a fim de ser possível o estabelecimento de discussões pertinentes sobre políticas públicas adequadas em prol do fortalecimento das instituições escolares e do exercício profissional dos professores.

\section{Referências bibliográficas}

ALVES, Maria T. G.; SOARES, José. F. Efeito-escola e estratificação escolar: o impacto da composição de turmas por nível de habilidade dos alunos. Educação em Revista, Belo Horizonte, V. 45, p. 25-58, 2007.

BRANDÃO, Zaia. Fluxos escolares e efeitos agregados pela escola. Em Aberto, Brasília, v. 17, p. 41, 2000.

BRASIL. MEC/INEP. Resultados do SAEB 2003 (Versão preliminar). Brasília, jun. 2004.

BRASIL. MEC. Prova Brasil 2007. Disponível em: <http://provabrasil.inep.gov.br>. Acesso em: 20 jan. 2009.

BRUNET, Luc. Clima de trabalho e eficácia da escola. In: NÓVOA, António (Coord.). As organizações escolares em análise. 2. ed. Lisboa: Dom Quixote, 1995. p. 123-140.

CERDEIRA, Diana. G. S. Mapeando o perfil docente de escolas de prestígio: uma contribuição para a compreensão do sucesso escolar. 2008. Dissertação (Mestrado em Educação) - PUC-Rio, Rio de Janeiro, 2008.

COSTA, Márcio; KOSLINSKI, Mariane C. Competing for public schools in Rio de Janeiro reflexions on a hidden quasimarket. In: Penser les marches scolaires. Genebra: Rappe Université de Genève, 2009. p. 1-22. Disponível em: <http://www.unige.ch/fapse/ ggape/seminaire/programme/progjeudi12/DaCostaKoslinski.pdf $>$. Acesso em: 12 dez. 2009.

CUNHA, Marcela. B.; COSTA, Márcio. O clima escolar de escolas de alto e baixo prestigio. In: REUNIÃO DA ASSOCIAÇÃO NACIONAL DE PÓS-GRADUAÇÃO E PESQUISA EM EDUCAÇÃO, 32., Anais... 2009, Caxambu-MG. Sociedade, cultura e educação: novas regulações, 2009.

FRANCO, Creso et al. Qualidade e equidade em educação: reconsiderando o significado de "fatores intraescolares". Ensaio: aval. pol. públ. Educ. [online], v. 15, n. 55, p. 277-298, abril 2007.

GHEDIN, Evandro. Professor reflexivo: da alienação da técnica à autonomia crítica. In: PIMENTA, Selma Garrido; GHEDIN, Evandro. Professor reflexivo no Brasil: gênese e crítica de um conceito. São Paulo: Cortez, 2002.

KLEIN, Ruben. Universalização do ensino básico. O Globo, Rio de Janeiro, 21 jan. 2007, p. 7. 
MORTIMORE, Peter. Can Effective Schools Compensate for Society? In: HALSEY, A. H.; LAUDER, H.; BROWN, P.; WELLS, A. S. (Ed.). Education: Culture, Economy, Society. Oxford: Oxford University Press, 1997. p. 476-487.

NÓVOA, Antônio. As organizações escolares em análise. Lisboa: Dom Quixote, 1995.

PORTAL DO ESTADÃO. Formação de professor deve mudar para melhorar a qualidade do ensino. 08/06/2009. Disponível em:

$<$ http://www.estadao.com.br/noticias/suplementos, formacaode-professor-deve-mudar-para-melhorar-qualidade-do-ensino,384364,0.shtm>. Acesso em: 15 nov. 2009.

ROSENTHAL, Robert; JACOBSON, Leonore. Pygmalion à L'École. Succès ou Échec Scolaire? Un Facteur Important. Le Prèjugé du Maître. Paris: Casterman, 1971.

MÁRCIA DE SOUSA TERRA BRITO, mestre em educação pela Universidade Federal do Rio de Janeiro, participante do Grupo de Estudos e Pesquisas dos Sistemas Educacionais (GESED/UFRJ), atua como professora da rede municipal de ensino do RJ. E-mail: marcinhapenha@hotmail.com
MARCIO DA COSTA, doutor em sociologia pelo Instituto Universitário de Pesquisa do Rio de Janeiro - IUPERJ, é membro do GESED - Grupo de Estudos dos Sistemas Educacionais, na UFRJ, e integra os grupos interinstitucionais de pesquisa denominados Observatório das Metrópoles e Observatório Educação e Cidade; atua nas áreas de sociologia da educação e política educacional. Suas publicações recentes mais importantes são Costa, M. Prestígio e hierarquia escolar: estudo de caso sobre diferenças entre escolas em uma rede municipal (Revista Brasileira de Educação, v. 13, p. 455-469, 2008), e Costa, M.; Koslinski, M. C. Entre o mérito e a sorte: escola, presente e futuro na visão de estudantes do ensino fundamental do Rio de Janeiro (Revista Brasileira de Educação, São Paulo, v. 11, n. 31, p. 133-154, 2006). E-mail: marcioc@pobox.com

Recebido em agosto de 2010 Aprovado em outubro de 2010 
clima escolar das escolas públicas do município do Rio de Janeiro

$\mathrm{O}$ artigo apresenta resultados de uma pesquisa realizada em escolas públicas do município do Rio de Janeiro que investigou a percepção dos professores sobre suas práticas pedagógicas, a fim de compreender se as características referentes ao clima e prestígio escolar podem influenciar o trabalho docente realizado nas escolas. Os achados sugerem que os professores tendem a mudar suas atitudes nas escolas em função da reputação destas e das imagens que constroem acerca de seu alunado. Fatores associados à contribuição da escola em promover ou acentuar as desigualdades escolares entre os alunos foram identificados, destacando-se diferenças no critério de oferta de vagas, perfil da gestão escolar, diferenças no tratamento dos conteúdos a serem ensinados e nas formas de avaliação. $\mathrm{O}$ trabalho indica que há um efeito bola de neve na tendência a que as escolas se tornem ambientes relativamente homogêneos.

Palavras-chave: prestígio escolar; clima escolar; hierarquias escolares

Teachers' practices and perceptions and their relations with prestige and school environment in public schools in the municipality of Rio de Janeiro

The article presents results of a research conducted in public schools in the municipality of Rio de Janeiro. It investigated the perceptions teachers have about their pedagogic practices, in order to understand if the characteristics that refer to the school environment and prestige can influence the teaching accomplished in the schools. The findings suggest that teachers tend to change their attitudes in the schools according to the schools' reputation and to the images they construct of their students. Factors associated with the school's contribution to promoting or emphasizing the inequalities among the students were identified, stressing differences in the criterion for offering vacancies, in the profile of school administration, differences in the treatment of the contents to be taught and in the forms of evaluation. The work indicates that there is a snowball effect by which the schools tend to become relatively homogeneous environments.

Key words: school prestige; school environment; school hierarchies

Facultad percepciones y prácticas y sus relaciones con el prestigio y el clima de la escuela de la ciudad de las escuelas públicas de Rio de Janeiro

El documento presenta resultados de una encuesta de las escuelas públicas en el municipio de Río de Janeiro, que investigo percepciones de los maestros sobre sus prácticas de enseñanza con el fin de comprender las características relacionadas con el clima escolar y la reputación, puede influir en la labor docente realizada en las escuelas. Los resultados sugieren que los profesores tienden a cambiar sus actitudes en las escuelas en función de su reputación y la creación de una imagen sobre sus estudiantes. Los factores asociados con la contribución de la escuela en la promoción o aumento de las desigualdades entre los estudiantes de la escuela fueron identificados, destacan las diferencias en los criterios de plazas escolares, el perfil de la gestión escolar, las diferencias en el tratamiento de los contenidos a enseñar y las formas de evaluación. Palabras clave: prestigio académico, clima escolar, jerarquías de la escuela.
Márcia de Sousa Terra Brito e Marcio da Costa

Práticas e percepções docentes e suas relações com o prestígio e 